Research Article

\title{
Design and dSPACE Implementation of a Simplified Fuzzy Control of a DC-DC Three-Level Converter
}

\author{
Hajar Doubabi $(\mathbb{D})$ and Issam Salhi \\ Cadi Ayyad University, PB 549 Av. Abdelkarim Elkhattabi, Gueliz, Marrakesh, Morocco \\ Correspondence should be addressed to Hajar Doubabi; hajardoubabi@gmail.com
}

Received 14 February 2021; Revised 3 June 2021; Accepted 10 June 2021; Published 22 June 2021

Academic Editor: Yang Li

Copyright (c) 2021 Hajar Doubabi and Issam Salhi. This is an open access article distributed under the Creative Commons Attribution License, which permits unrestricted use, distribution, and reproduction in any medium, provided the original work is properly cited.

\begin{abstract}
The design of an efficient DC-DC converter depends critically on its suitable control. In this paper, a new simplified output tracking control strategy for a DC-DC three-level boost converter is presented. The proposed strategy is characterized by its good tracking performances, its simplicity of design, and the stability that is ensured over the entire operating range. Thanks to (i) the adopted Takagi-Sugeno (TS) fuzzy approach; (ii) the small-signal model derived under the large domain of operating conditions, and (iii) the proportional-integral (PI) controllers' merit. After introducing the three-level boost converter topology, the operating principles and mathematical modeling are addressed. Then, the proposed output control strategy is developed based on the PI control and the TS fuzzy approximation. A controller ensuring the capacitor voltages balancing has been also introduced in this paper. Experimental results using dSPACE (DS1104) and a laboratory prototype of three-level boost converter demonstrate the flexibility of the proposed controller, its reference tracking capability, and its ability to satisfy the performance specification over the whole operating range of the system.
\end{abstract}

\section{Introduction}

The last three decades witnessed an incredible development in power conversion circuits, particularly pulse width modulation (PWM) DC-DC converters and their spread in almost all sectors including telecommunication, medicine, transport, lightning technology, space and avionics, and renewable energy. Such a variety of applications imposed new challenges and a large scale of requirements on power conversion. Accordingly, a significant amount of research is taking place to develop new circuit structures, modern power semiconductor devices, and advanced control techniques. Diverse DC-DC converters topologies have been addressed in [1-32] and categorized depending on their power conversion applications.

Compared to the classical converter topologies, a DCDC three-level boost converter (TLBC) is a fundamental power converter that can efficiently step up the input voltage and synthesizes voltage waveform with reduced harmonics. The electrical schematic diagram of a DC-DC TLBC is depicted in Figure 1. The DC-DC converters exhibit nonlinear dynamic behavior, which dramatically increases the complexity of their modeling and control [2].

Different studies in the literature have been derived to investigate the DC-DC TLBC output voltage control [3-5]. In [3], a controller-based sliding mode has been developed for output control of a TLBC connected to a fuel cell. The controller presents good performance in terms of trajectory tracking and disturbance rejection; however, the chattering problem, the variable switching frequency, and the required prior knowledge about the uncertainty bounds are considered as major drawbacks of sliding mode control. In [4], a model predictive control strategy has been proposed for a photovoltaic system incorporating TLBC. The study emphasized the effectiveness and robustness of this strategy through the obtained results. Nevertheless, a model predictive controller is very sensitive to parameters variation. The authors in [5] have studied the TLBC with a modelbased control technique based on the flatness principle for fuel cell applications. The developed control algorithm based 


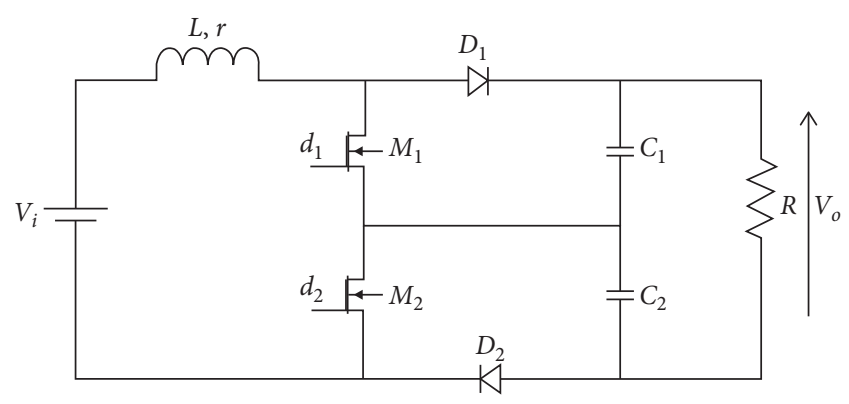

Figure 1: Three-level boost converter circuit.

on the propriety of flatness of the system has ensured good output control and dealt with the stabilization problem of the system. These have been demonstrated theoretically and experimentally. However, an accurate mathematical model is required, which increases the complexity of algorithm calculations and the cost of controller implementation and hence limits its application on simple systems.

Developing advanced control strategies using a fuzzy approach for different systems including DC-DC converters have attracted much attention over recent years [6-8]. This is due to its adaptive control ability of the complex nonlinear systems. Moreover, studies in $[9,10]$ demonstrated how the fuzzy control can maintain the classical control advantages (feasibility, low computational complexity, etc.) and improve its dynamic performances.

A convenient and efficient control strategy merging PI control and fuzzy control-based Takagi-Sugeno approach (TSF-PI) has been proposed and examined in the literature [12-15]. It is basically developed by blending the local PI controllers properly through the fuzzy membership functions. It used the so-called local modeling or multimodel representation that is of strong interest [11]. Based on linearization around different operating points, the nonlinear systems are modeled and the resulted models enable the employ of classical PI control strategy to design local controllers. This TSF-PI controller has shown improved performance in many processes. In [12], an electrical load TSF-PI controller has shown strong adaptability in controlling a micro-hydroelectric power plant under different working conditions. In [13], adaptive power control-based TSF was developed for plug-in electric vehicles charging connected to the smart grid. This has enhanced the frequency stabilization performance for the smart grid. In [14], the TSF logic method is used to compensate the current harmonics and to control the DC-bus voltage of the capacitor in a three-phase shunt active power filter. In [15], the TSF-PI controller was implemented to achieve the output tracking of the conventional DC-DC boost converter. The obtained results have emphasized the robustness and efficiency of this control strategy.

As it can be deduced, the TSF-PI control strategy has many advantages including simple handling of the system nonlinearity by using the TSF approach and the possibility of utilizing classical controllers (PI), which reduces the mathematical complexity and the computational cost as well as facilitates the implementation. Moreover, as introduced in [16] and as resulted in [15], the TSF-PI controller ensures high control performance in the whole operating range of the system. Motivated by these merits, a TSF-PI controller was developed and experimentally implemented as presented in this paper.

It is worth mentioning that for a practical TLBC, a feedback controller is not enough and has not the ability to achieve the desired regulation performances. In other words, the TLBC is known for the inherent drawback of capacitor voltages unbalance [17]. This problem influences the overall converter operating; therefore, it is critical to cope with it. This can be done by including a voltage balancing controller into the system closed loop. The literature has reported on different voltage balancing control strategy. Some authors propose strategies based on (i) inductor current sensing [18], which can through a proposed sampling process detect the voltage unbalance; however, this method demands a high sampling accuracy as well as for light loads a sampling error may lead to system damage; (ii) capacitors voltage sensing [17], which is the most used thanks to its simplicity and reliability, so as through a PI controller, the capacitors voltage difference is set to be zero.

In this paper, a TLBC prototype has been designed and built to experimentally verify the proposed control strategy. First, the experimental operating characteristic describing the nonlinear behavior of the TLBC was derived. Then, the linearization around given operating points was performed, which helps in the system modeling. The proper transfer functions, modeling the TLBC circuit within the given operating points, were identified. Afterwards, PI controllers were synthesized based on the obtained transfer function models. They present good performance around the nominal operating point for which they were designed. For optimal tuning of these local PI controllers using TS fuzzy, a TSF-PI controller was developed. Then, a controller ensuring the capacitor voltages balancing, using a capacitor voltages sensing method has been integrated and validated experimentally.

The proposed global control scheme is introduced in this paper, and the experimental results reflecting its flexibility, robustness, and its ability to achieve specification over a range of operating points are presented.

Hence, the main contributions of this proposed work are as follows:

(i) Modeling of a DC-DC three-level boost converter

(ii) Development of a new output tracking control method for a DC-DC three-level boost converter. This method has the following merits: (i) the ability to cope with the nonlinearity of the converter by means of a TS fuzzy approximation, (ii) the use of PI controllers in order to take advantage of their performances, and (iii) ensure the overall global stability of the system 
(iii) Experimental validation of the proposed control method under time-varying operating point and load disturbances in real time using dSPACE (DS1104) board and a three-level boost converter laboratory prototype.

This paper is structured as follows. The topology, principle of operation, and the experimental prototype of TLBC are described in Section 2. In Section 3, the local TLBC identification based on transfer function models is addressed. Section 4 examines the capacitor voltages balance control of TLBC and presents the corresponding results. The output voltage control is described in detail in Section 5 using the PI controller, and in Section 5 using the proposed TSF-PI controller and then the experimental results that validate the controller operation are discussed. Finally, a conclusion is given in Section 6 .

\section{TLBC Description}

2.1. Topology. Generally, increasing the power level in the conventional boost DC-DC converter results in higher switching losses, which is notably marked in switches needing to withstand higher DC output voltages. This voltage stress of switches can be successfully reduced by connecting together two cascaded capacitors and two cascaded switches as the typical structure depicted in Figure 1 of the so-called three-level boost DC-DC converter. It is composed of power switches (MOSFETs) $M_{1}$ and $M_{2}$, diodes $D_{1}$ and $D_{2}$, an inductor $L$, output voltage dividing capacitors $C_{1}$ and $C_{2}$, an equivalent series resistance (ESR) of inductor $r$, load resistor $R$, an input voltage $V_{i}$, and an output voltage $V_{o}$. The switches $M_{1}$ and $M_{2}$ are driven by two pulse width modulation (PWM) with the same duty cycle $(d)$, but they are phase-shifted by $180^{\circ}$. An example of experimental PWMs controlling the switches is illustrated in Figure 2 with a duty ratio of $50 \%$ and a switching frequency of $32 \mathrm{kHz}$. In this converter topology, the output stage is divided so the switching devices withstand only half DC output voltage if the capacitor voltage's balance is ensured. Hence, low switching losses and high efficiency are achieved as lowwithstanding-voltage switches, often have lower cost and reduced equivalent series resistance than the high-withstanding-voltage ones, and are used in this converter circuit. It is also worth stressing that the TLBC was named threelevel converter as the voltage across the inductor has three levels due to the $180^{\circ}$ phase-shift control signals [19], which greatly minimize the inductor current ripple. The number of switches and capacitors forming this circuit was selected depending on the converter level. Mainly, the $N$-level boost converter will have $(N-1)$ output capacitors and $2(N-1)$ switches (MOSFETs and diodes) [20].

Thus, the main advantages of this presented topology compared to the conventional one can be summarized as follows [33]:

(i) Lower voltage stress on semiconductor components

(ii) Smaller harmonic distortion and lower EMI

(iii) Higher efficiency

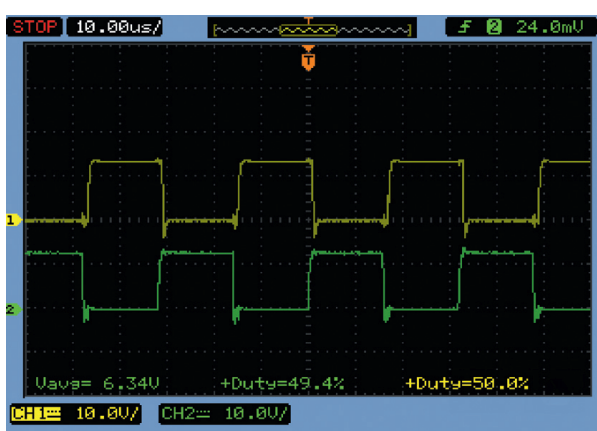

FIgURE 2: The PWM signals monitoring the switches $M_{1}$ and $M_{2}$.

However, this topology has some disadvantages such as

(i) The need of using more semiconductor components

(ii) Output capacitors voltages unbalance possible occurrence

2.2. Principle of Operation. To understand the operating process of the TLBC, the corresponding circuit states are presented in Figure 3. As can be seen, four principal states result from the different switching combinations in the circuit system.

In state 1 (Figure $3(\mathrm{a})$ ), both switches $\left(M_{1}\right.$ and $\left.M_{2}\right)$ are closed; hence, the inductor is in charging mode and its current raising rate $\left(d i_{L} / d t\right)$ is always positive. The capacitors $C_{1}$ and $C_{2}$ get discharged through the load.

In state 2 (Figure $3(\mathrm{~b})$ ), the upper switch $M_{1}$ is closed while the lower one is open. The inductor can be in charging or discharging mode as the current raising rate may be positive or negative. This depends on whether the input voltage is higher or lower than half of the output voltage (as $V_{c 1}=V_{c 2}=1 / 2 V_{o}$ ). In this state, the capacitor $C_{2}$ is in charging mode while the other capacitor $C_{1}$ is discharging.

The same applies to state 3 (Figure 3(c)); when the lower switch $M_{2}$ is closed and the upper $M_{1}$ is open, the inductor can be in charging or discharging mode and its current raising rate may be positive or negative. The capacitor $C_{1}$ is in charging mode while the other capacitor $C_{2}$ is discharging.

In state 4 (Figure $3(\mathrm{~d})$ ), both switches $\left(M_{1}\right.$ and $\left.M_{2}\right)$ are open; thus, the inductor is in discharging mode and the current raising rate is always negative as in the boost converter the output voltage is higher than the input. The capacitors $C_{1}$ and $C_{2}$ are in charging mode to supply the load.

In the continuous conduction mode, the voltage conversion ratio of the TLBC is the same as the conventional BC and expressed as follows [21]:

$$
V_{o}=\frac{V_{i}}{(1-d)}
$$

Figure 4 illustrates the main waveforms of the TLBC for the two possible operating cases. Figure 4(a) shows the case when $V_{i} \geq 1 / 2 V_{o}$ and Figure 4(b) shows the case when $V_{i}<1 /$ $2 V_{o}$. The capacitor voltages are assumed to be balanced $\left.<V_{c 1}\right\rangle=\left\langle V_{c 2}>\right.$. 


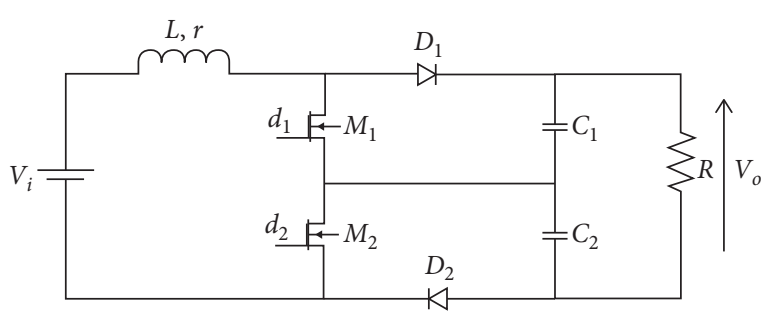

(a)

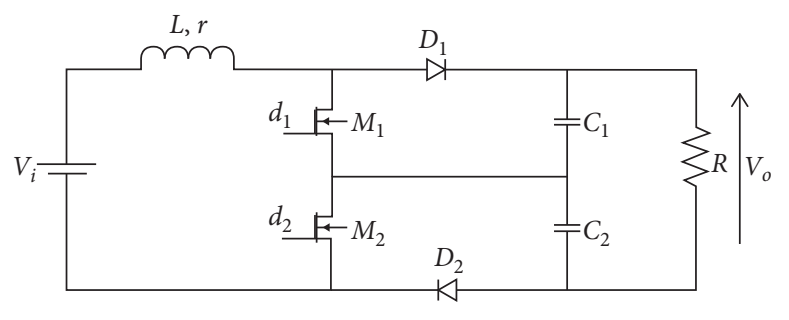

(c)

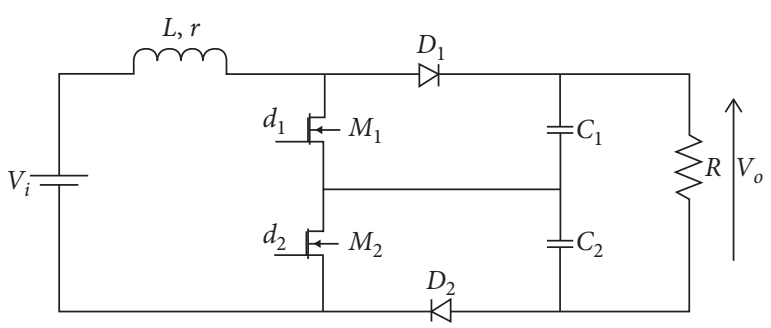

(b)

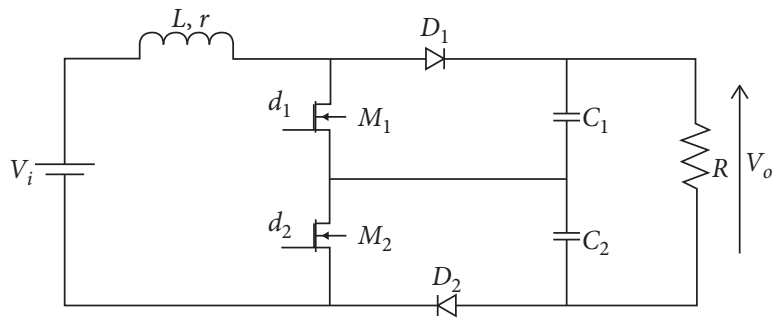

(d)

Figure 3: The four operating states of TLBC. (a) $M_{1}, M_{2}$ on; $D_{1}, D_{2}$ off, (b) $M_{1}, D_{2}$ on; $D_{1}, M_{2}$ off, (c) $D_{1}, M_{2}$ on; $M_{1}, D_{2}$ off, and (d) $D_{1}, D_{2}$ on; $M_{1}, M_{2}$ off.

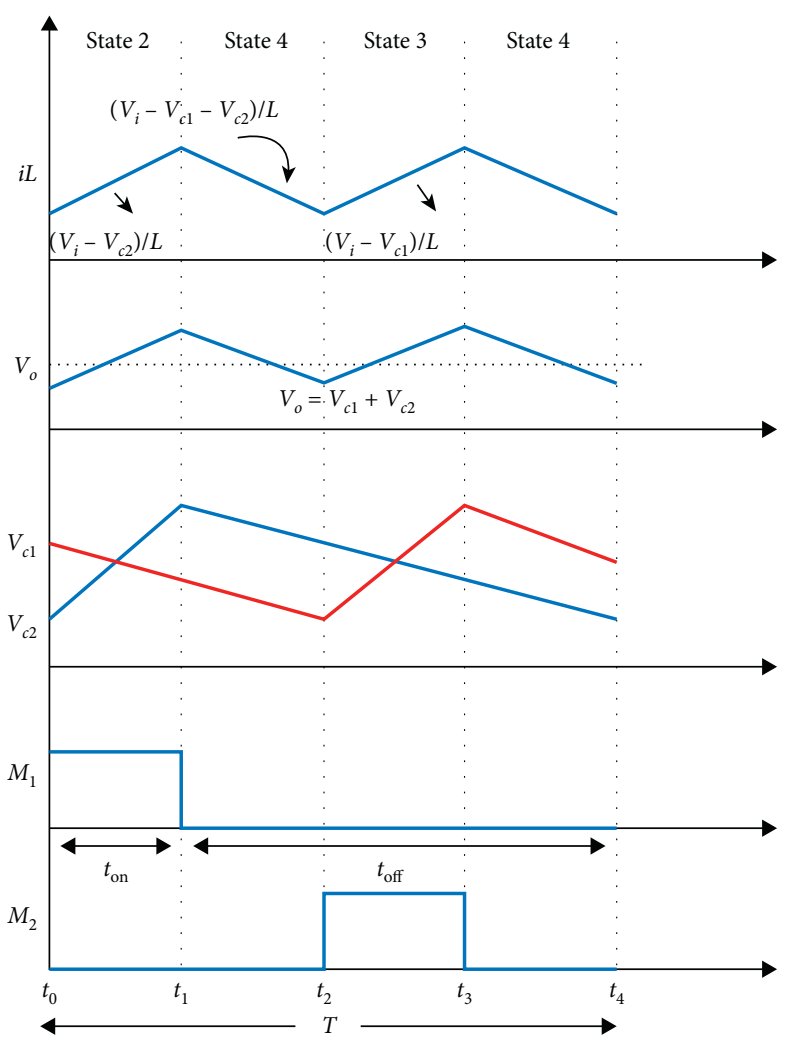

(a)

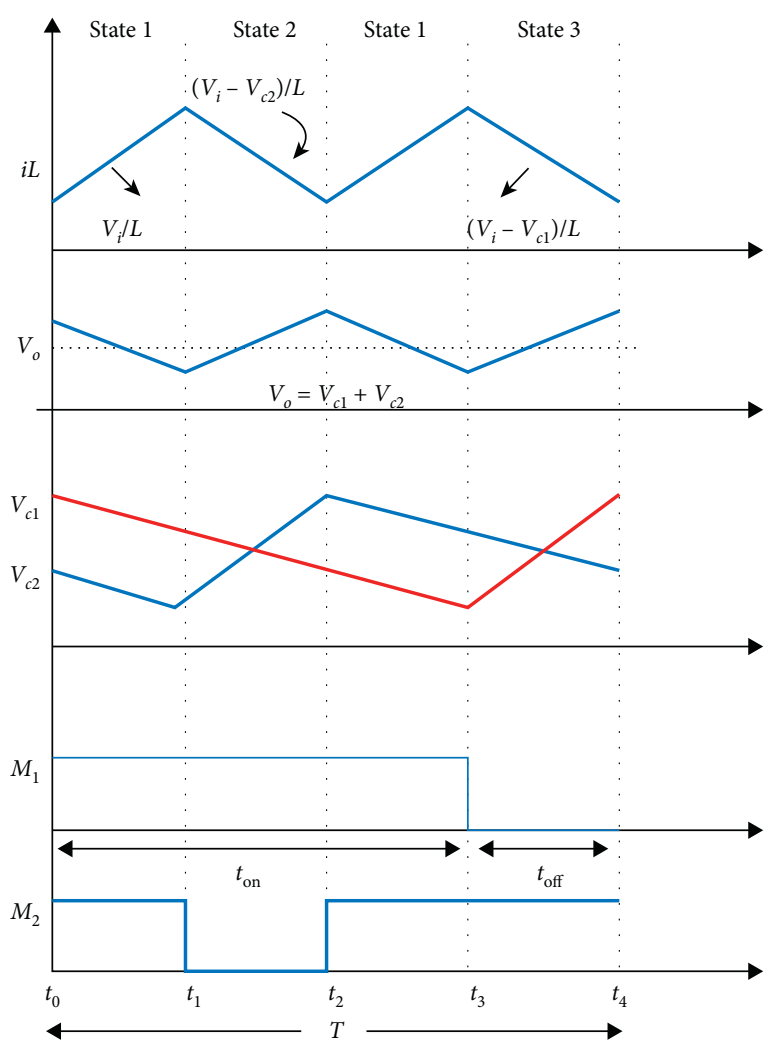

(b)

FIgURE 4: Typical waveforms of the TLBC, including the inductor current, the output voltage, the capacitor voltages, and the control signal of the switches for the case of (a) $V_{i} \geq 1 / 2 V_{o}$ and (b) $V_{i}<1 / 2 V_{o}$. 
The equations characterizing the CBTN in both operating cases can be given as follows [19].

Case 1. $V_{i} \geq 1 / 2 V_{o}$.

(i) The voltage gain is

$$
\left(V_{i}-\frac{V_{o}}{2}\right) \cdot d=-\left(V_{i}-V_{o}\right) \cdot(0,5-d) \Longleftrightarrow \frac{V_{o}}{V_{i}}=\frac{1}{1-d} \text {. }
$$

(ii) The inductor ripple current is

$$
\Delta i_{L}=\frac{V_{i}}{2 \cdot L \cdot f} \cdot \frac{d \cdot(1-2 \cdot d)}{1-d} .
$$

(iii) The output voltage ripple is

$$
\Delta v_{o}=\frac{2 \cdot i_{o} \cdot(0.5-d)}{C \cdot f}=\frac{V_{i} \cdot(1-2 \cdot d)}{(1-d) \cdot R \cdot C \cdot f} .
$$

(iv) The voltage and current stresses of the power MOSFETs and diodes are

$$
\left\{\begin{array}{l}
v_{M, \text { max }}=v_{d, \max }=v_{c, \text { max }}=\frac{V_{i}}{1-d}+\frac{V_{i}}{2 \cdot R \cdot C \cdot f} \\
i_{M, \text { max }}=i_{d, \text { max }}=i_{L, \text { max }}=I_{L}+\frac{\Delta i_{L}}{2} .
\end{array}\right.
$$

Case 2. $V_{i}<1 / 2 V_{o}$.

(i) The voltage gain is

$$
V_{i} \cdot(d-0,5)=-\left(V_{i}-\frac{V_{o}}{2}\right) \cdot(1-d) \Longleftrightarrow \frac{V_{o}}{V_{i}}=\frac{1}{1-d} \text {. }
$$

(ii) The inductor ripple current is

$$
\Delta i_{L}=\frac{V_{i}}{2 \cdot L \cdot f} \cdot(2 \cdot d-1) \text {. }
$$

(iii) The output voltage ripple is

$$
\Delta v_{o}=\frac{2 \cdot i_{o} \cdot(d-0,5)}{C \cdot f}=\frac{V_{i} \cdot(2 \cdot d-1)}{(1-d) \cdot R \cdot C \cdot f} .
$$

(iv) The voltage and current stresses of the power MOSFETs and diodes are

$$
\left\{\begin{array}{l}
v_{M, \text { max }}=v_{d, \text { max }}=v_{c, \text { max }}=\frac{V_{i}}{1-d}+\frac{d \cdot V_{i}}{2 .(1-d) \cdot R \cdot C \cdot f}, \\
i_{M, \text { max }}=i_{d, \text { max }}=i_{L, \text { max }}=I_{L}+\frac{\Delta i_{L}}{2} .
\end{array}\right.
$$

2.3. Experimental Prototype Description. A TLBC prototype with the parameters listed in Table 1 has been built. Its circuit is chiefly made up of a control circuit and a power switching stage. The control circuit consists of a gate driver IR2110 and the bootstrap circuit ensuring proper operation of the driver. In the TLBC circuit, the source node of the MOSFET M1 is floating; hence, the gate driver was selected to guarantee an independent high- and low-side switches drive as well as complete isolation between the control circuit ground and the power stage ground. A good selection of the drive stage is critical to achieving optimal switching performance and efficient power conversion. The power switching stage incorporates the inductance, the capacitors, the MOSFETs, and the diodes. The inductor and capacitors were selected with low ESR $(\mathrm{m} \Omega)$, which is an important design consideration. One of the major sources of increased switching losses in the converters is the reverse recovery effect occurring in the p-n junctions [22]. Schottky diodes were used as they are known for their very little reverse recovery effect compared to other types. More details about the adopted component in the TLBC circuit are provided in Table 2. The experimental test bench is shown in Figure 5. Different algorithms can be implemented utilizing the PC running with MATLAB/Simulink software. The dSPACE DS1104 board was employed as an interface between the converter circuit and the PC. It enables the PWMs generation and the data acquisition from sensors and can handle the global control process of the converter circuit.

\section{TLBC Modeling}

The TLBC operating characteristics is a helpful curve, basically used for defining the operation of the converter and modeling its behavior, which results in optimal converter identification. The TLBC has two independent inputs that are the input voltage and the duty cycle (the control action) and an output that is the output voltage. However, the input voltage is considered constant in our study. Hence, we examined the TLBC output voltage behavior toward the control action. For a resistive load $(24.7 \Omega)$ and different values of the duty cycle, the output voltage is measured. This was done for the TLBC circuit implemented in MATLAB/ Simulink as well as for the experimental prototype. Therefore, the output voltage versus the duty cycle was plotted as shown in Figure 6. As can be seen from the simulated curve, the TLBC stops boosting beyond a maximum duty cycle. For a practical TLBC, the power switches limitations (i.e., thermal limitations, voltage, and current they can handle), and the diode voltage drop may impose a limit not to exceed. For the studied prototype, an upper limit of $75 \%$ on the duty cycle was found as shown by the experimental curve to ensure the correct operation of the converter [23].

It can be seen from the plotted characteristic in Figure 6 that the TLBC exhibits nonlinear behavior, which increases its modeling and control complexity. In the literature, various studies have been focused on modeling the TLBC using the state space approach $[4,24]$. Nevertheless, the small-signal linearization is one of the most suitable and simplest approaches that allow for a well-defined model enabling proper control. It is based on identifying the system around particular operating points. In this regard, the TLBC operating characteristic is first divided into three linear 
TABLE 1: DC-DC TLBC parameters.

\begin{tabular}{lcc}
\hline Parameter & Value & Unit \\
\hline$V_{i}$ & 12 & $\mathrm{~V}$ \\
$L$ & 500 & $\mu \mathrm{H}$ \\
$r$ & 8 & $\mathrm{~m} \Omega$ \\
$C_{1}$ & 100 & $\mu \mathrm{F}$ \\
$C_{2}$ & 100 & $\mu \mathrm{F}$ \\
$R$ & 24.7 & $\Omega$ \\
$f_{s}$ & 32 & $\mathrm{kHz}$ \\
\hline
\end{tabular}

TABle 2: Component list of the TLBC circuit.

\begin{tabular}{lcc}
\hline Component & Part number & Parameters \\
\hline $\begin{array}{l}\text { MOSFETs }(M 1 \\
\text { and } M 2)\end{array}$ & IRFB4310 & $100 \mathrm{~V}, 140 \mathrm{~A}$, and \\
MOSFET gate & IR2110 & $5.6 \mathrm{~m} \Omega$ \\
driver & & - \\
Diodes (D1 and & STPS20120D & $120 \mathrm{~V}, 20 \mathrm{~A}$ \\
$D 2)$ & KEMET SC-15-05J & $500 \mu \mathrm{H}, 15 \mathrm{~A}$ \\
Inductor & EKXG201ELL101ML20S & $100 \mu \mathrm{F}, 100 \mathrm{~V}$ \\
Capacitors &
\end{tabular}

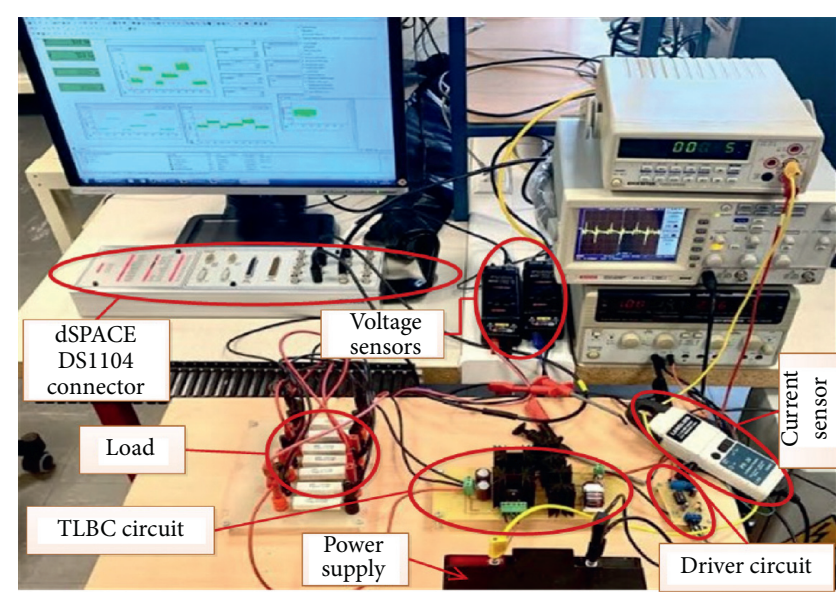

Figure 5: The experimental test bench.

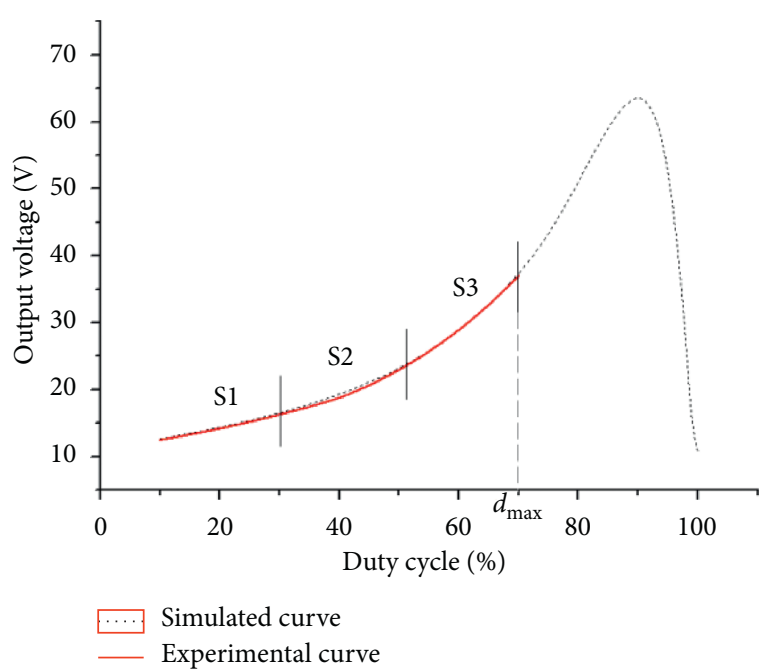

FIgURE 6: Three-level boost converter operating characteristic. subintervals $\left[S_{1}, S_{2}, S_{3}\right.$ ] (as shown in Figure 6), and then the linear models, corresponding to each subinterval, were separately identified.

The TLBC is characterized by a control-to-output transfer function. The latter was identified for each of the three linear subintervals using the following procedure:

(i) The TLBC circuit was used in open loop.

(ii) In each of the three linear zones (i.e., around three different operating points), a small variation of the duty cycle (of $1 \%$ or $2 \%$ ) was applied. The resultant output responses corresponding to each zone are shown in Figure 7. Zoomed-in views of the step-up transient are also given in images 1,2 , and 3 for better clarification. It can be seen that the duty cycle variation engenders a sudden change in the output voltage characterized by a short transient state.

(iii) The obtained data was loaded and processed by MATLAB's System Identification Toolbox to extract the transfer function for each linear subinterval. This toolbox allows a suitable identification of the system.

Tests using MATLAB's System Identification Toolbox were performed to reach a high "fit to estimation data" and hence selecting the most appropriate transfer functions representation. The resultant transfer function models are presented in Table 3 and plotted as depicted in Figure 7.

Additionally, Table 4 reports the numerical values of the performance specification corresponding to each transfer function model. Note that the dynamical differences between the three obtained transfer functions are justified because the studied system is nonlinear, as already pointed out in this paper.

\section{Voltage Balance Control of TLBC}

As shown in Figures 1 and 5, the TLBC circuit incorporates two capacitors that operate to alternately provide energy to the load. Such operation can be ensured theoretically or in simulation. However, this is not straightforward in a practical implementation. In addition to the mismatched capacitors, the nonideality and variations of the control circuit and the driver would result in a slight difference in the PWM signals monitoring the switches (as depicted in Figure 2), which engender the unbalance of the amount of energy supplied by the capacitors to the load. Specifically, the capacitor voltages become unequal, and their waveform will be asymmetrical. This inherent issue of the TLBC circuit prevents its proper operation and can lead to filter damage. To resolve this problem, a voltage balancing control strategy was adopted.

The voltage balancing control strategy principal task is to keep monitoring both capacitor voltages and suitably increase or reduce the switching durations that the voltage equality can be achieved. Figure 8 depicted how the balance control scheme can be integrated into the control loop of the TLBC. 


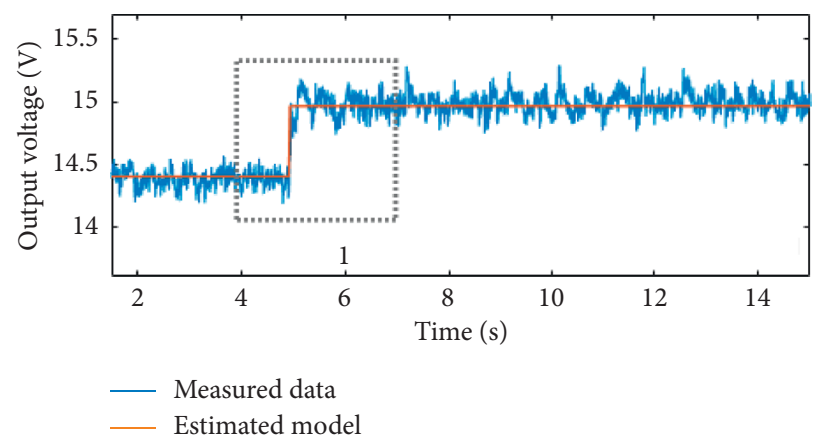

(a)

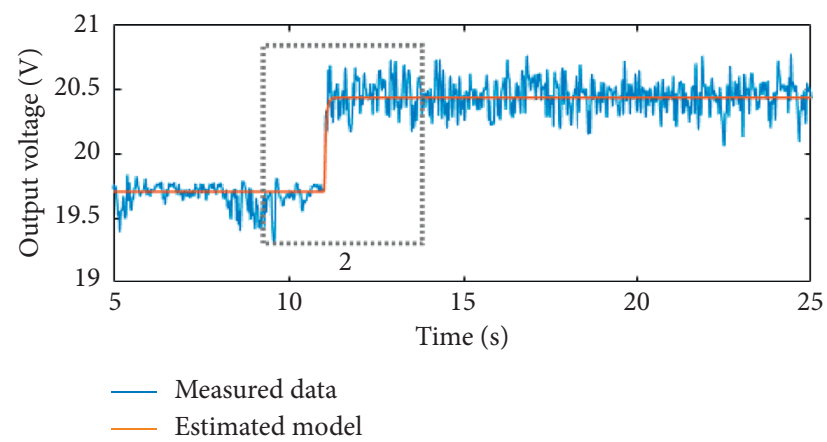

(b)
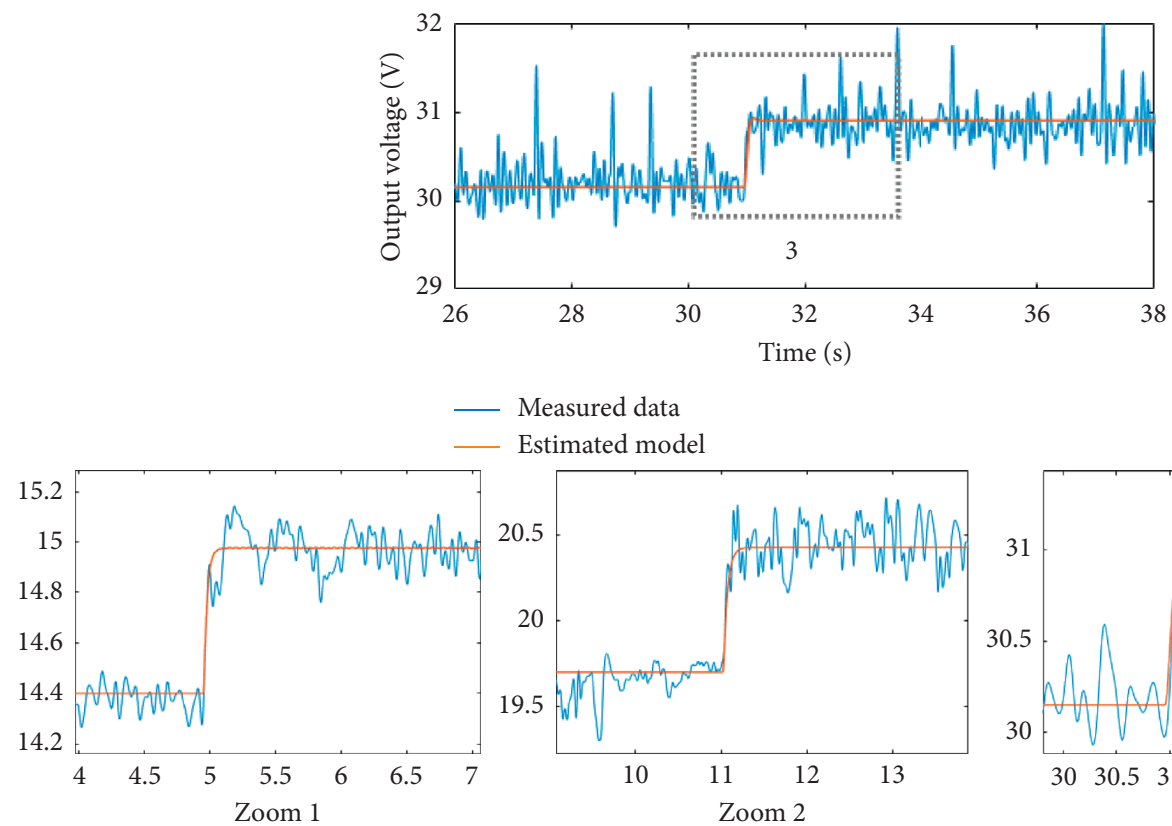

(c)

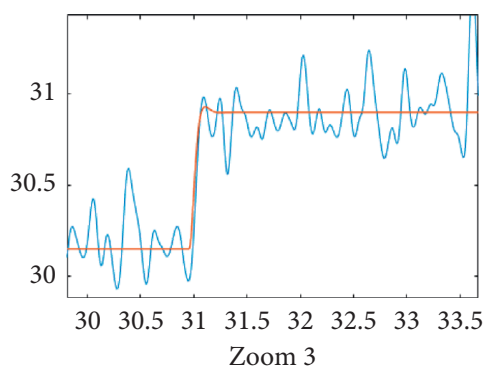

Figure 7: Output voltage response to duty cycle variations. (a) From $18 \%$ to $20 \%$, (b) from $40 \%$ to $41 \%$, and (c) from $60 \%$ to $61 \%$.

The proposed balance control works as follows. (i) It begins by sensing the voltages across both capacitors $(V c 1$ and $V c 2$ ) as the balance control loop's purpose is to adjust $V c 1$ and $V c 2$ to be equal. (ii) The difference between the $V c 1$ and $V c 2$ signals is compared to the reference voltage set zero where the resultant error is the PI controller input, and then the generated output is the compensation signal $\Delta$ d. (iii) This signal is added to the output signal $d$, generally provided by the output voltage controller to achieve both the output voltage regulation and the capacitors voltage balancing. The resultant signal of summation passed directly through the PWM generator to get the drive signal $d 2$.

Specifically, assuming $V c 2>V c 1$, then $d 1$ will have a smaller value of duty cycle than the $d 2$. This means that $M 2$ will turn on for a longer duration than $M 1$ and hence, more energy will be discharged from $C 2$ than $C 1$. This will increase $V c 1$ and reduce $V c 2$ until reaching a value below half the output voltage; then the reverse occurs. Hence, the capacitor voltages keep balanced. 
TABLE 3: Transfer function model corresponding to each subinterval $\left(S_{1}, S_{2}, S_{3}\right)$.

\begin{tabular}{lccc}
\hline Subinterval & Output voltage interval (Volt) & Duty cycle interval (\%) & Transfer function model \\
\hline$S_{1}$ & $(12-16)$ & $(10-30)$ & $1.535 .10^{6} /\left(s^{2}+398.9 s+5.468 .10^{4}\right)$ \\
$S_{2}$ & $(16-23)$ & $(30-51)$ & $2.811 .10^{5} /\left(s^{2}+199.2 s+3854\right)$ \\
$S_{3}$ & $(23-41)$ & $(51-70)$ & $5.826 .10^{4} /\left(s^{2}+43.56 s+935.2\right)$ \\
\hline
\end{tabular}

TABle 4: Performance specification of the estimated transfer function model.

\begin{tabular}{lccr}
\hline Subinterval & $S_{1}$ & $S_{2}$ & $S_{3}$ \\
\hline Overshoot ratio (\%) & 0.58 & 0 & 4.12 \\
Rise time (s) & 0.011 & 0.102 & 0.071 \\
Settling time (s) & 0.018 & 0.186 & 0.194 \\
Peak time (s) & 0.025 & 0.300 & 0.145 \\
\hline
\end{tabular}

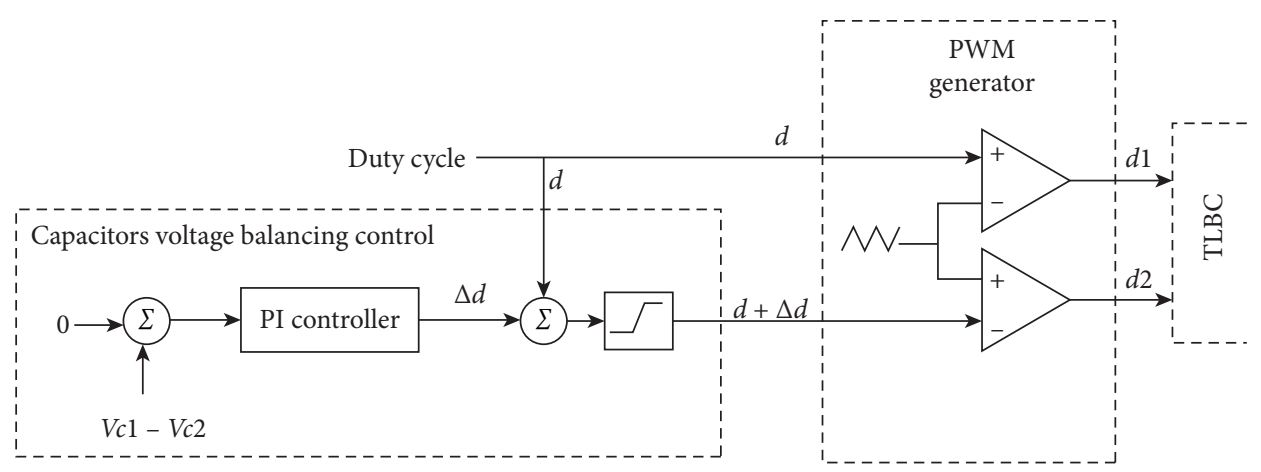

FIGURE 8: Block diagram of the proposed voltage balancing control scheme.

The PI controller used in the closed-loop intended for capacitor voltage balancing control was derived using the following synthesis process:

(i) In the open-loop TLBC circuit, a small variation of the duty cycle from $40 \%$ to $42 \%$ was applied, the output voltage changes from $21.5 \mathrm{~V}$ to $22.3 \mathrm{~V}$, and the obtained experimental waveform of the difference $V c 1-V c 2$ was recorded as shown in Figure 9. (ii) The transfer function identifying this waveform was deduced using MATLAB's System Identification Toolbox as expressed by equation (10). (iii) For the obtained transfer function model, the PI controller parameters were synthesized as shown in equations (11) and (12) using the Naslin method.

$$
\begin{aligned}
F(s) & =\frac{2.811 .10^{5}}{s^{2}+199.2 s+3854} \\
C_{\mathrm{PI}} & =K_{p}\left(1+\frac{1}{T_{i} s}\right)
\end{aligned}
$$

where

$$
\left\{\begin{array}{l}
K_{p}=0.006 \\
T_{i}=0.014 s
\end{array}\right.
$$

Figure 10 shows the experimental waveform of $V c 1$ and $V c 2$ before and after incorporating the capacitors voltage balance control. Before, $V c 1$ and $V c 2$ were not balanced owing to the aforementioned reasons. After the use of the balance controller, it can be observed that the proposed controller works well and can both detect the capacitor voltages unbalance and achieve the balance.

\section{Output Voltage Control of TLBC Using a PI Controller}

The principal purpose of the proposed controller is disturbance rejection and accurate set-point tracking over the system operating domain. The control system synthesis typically builds on the model. Using the converter model identification, the obtained transfer function models (TFMs) are utilized to design local controllers around given operating points. Specifically, a PI controller is designed for each of the three TFMs. Owing to its simplicity of implementation and large applicability, the PI controller type is selected. The global block diagram of the TLBC closed loop is shown in Figure 11.

The parameters of PI controllers " $K_{p}$ " and " $K_{i}$ " have been set using the Naslin polynomial method [25]. The controller in the standard form presented by the equation (11) is selected. The parameters were calculated to satisfy the following requirements:

(i) Zero tracking error

(ii) Fast settling time (around $200 \mathrm{~ms}$ )

(iii) Maximum overshoot of $10 \%$

(iv) Phase margin $(\mathrm{PM}) \geq 45^{\circ}$ and gain margin (GM) $\geq 5 \mathrm{~dB}$.

Table 5 presents the resultant values of $K_{p}$ and $K_{i}$, corresponding to the PI controllers (PI1, PI2, and PI3) 


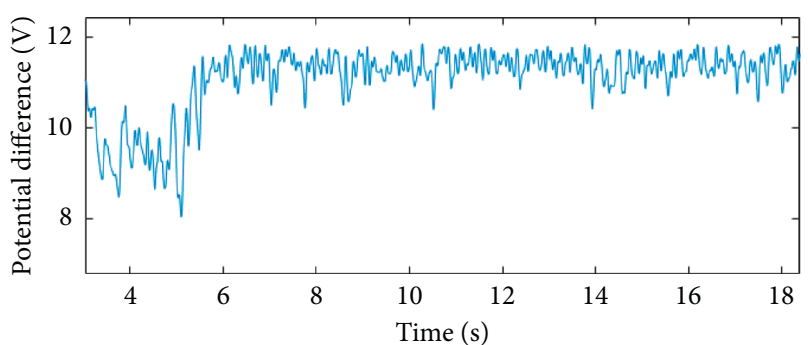

FIgURE 9: Experimental waveform of the difference $V c 1-V c 2$ response to a change in the duty cycle.

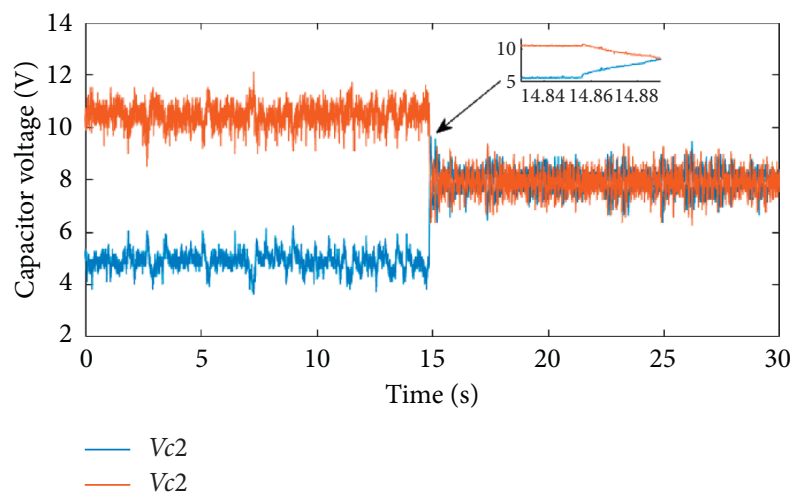

FIgURE 10: The experimental waveform of $V c 1$ and $V c 2$ before and after incorporating the capacitor voltages balance control.

designed for the three TFMs, respectively. The stability of the designed PIs is typically guaranteed since the PM and GM corresponding to each PI are given based on the Bode diagram as follows:

$$
\begin{array}{ll}
\text { PI1: } \mathrm{PM}=53^{\circ} & \mathrm{GM}=\inf \mathrm{dB}, \\
\text { PI2: } \mathrm{PM}=62^{\circ} & \mathrm{GM}=\inf \mathrm{dB}, \\
\text { PI3: } \mathrm{PM}=58^{\circ} & \mathrm{GM}=\inf \mathrm{dB} .
\end{array}
$$

Figure 12 presents the output voltage response of the closed-loop system under MATLAB/Simulink and showing the ability of the resultant PI controllers in accurately tracking the reference. It is clearly seen that around the operating point for which they are designed, the PI controllers present good performances and the system output tracks the reference voltage.

Nevertheless, a PI controller has generally a limited validity domain, and its use out of its operating point neighborhoods results in poor performances [26]. In addition, the nonlinearity of the studied converter makes it hard to ensure the whole system stability and satisfy the desired specification over the operating range using conventional PI controller. Therefore, improved control architecture is worthy to be adopted. In this regard, we intended in this work to design an improved controller based on an intelligent structure (TS fuzzy) guaranteeing optimal performances over the wide system operating range, as well as preserving the merits of PI control.

\section{Output Voltage Control of TLBC Using TS Fuzzy Controller}

6.1. TS Fuzzy Control Principal. The proposed controller is based on the parameters $\left(K_{p}\right.$ and $\left.K_{i}\right)$ tuning of PI controller depending on the working operating point. In other words, it can be described as a multicontroller with a selection law based on fuzzy logic, as shown in Figure 13. Accordingly, a TSF-PI controller, guaranteeing good performance over the entire operating interval of the system, is developed.

For a nominal value of the output voltage $V_{\text {out }}$, the fuzzy system has the following form:

$$
\text { Rule }^{i}: \operatorname{IF} \bar{V}_{\text {out }} \in S_{i} \quad \text { THEN } K_{p i} \text { and } K_{i i} \text {, }
$$

where $i=1,2, \ldots, r ; r$ is the number of fuzzy rules, in our case $r=3$, and $S_{i}$ is the $i$ th fuzzy set. Using a standard fuzzy inference method that uses a singleton fuzzifier, product inferred, and weighted average defuzzifier, the fuzzy system outputs can be expressed as follows:

$$
\left\{\begin{array}{l}
K_{p}=\frac{\sum_{i=1}^{r} \mu_{i}\left(\bar{V}_{\text {out }}\right) K_{p i}}{\sum_{i=1}^{r} \mu_{i}\left(\bar{V}_{\text {out }}\right)}, \\
K_{i}=\frac{\sum_{i=1}^{r} \mu_{i}\left(\bar{V}_{\text {out }}\right) K_{i i}}{\sum_{i=1}^{r} \mu_{i}\left(\bar{V}_{\text {out }}\right)},
\end{array}\right.
$$

where $\bar{V}_{\text {out }}$ is the premise variable and $\mu$ is the normalized membership function. $\mu_{i}\left(\bar{V}_{\text {out }}\right) / \sum_{i=1}^{r} \mu_{i}\left(\bar{V}_{\text {out }}\right) \geq 0$ are the normalized weights.

The TSF-PI controller provides the proper values of $K_{p}$ and $K_{i}$ for a given output voltage. This is done by combining, in a nonlinear form (using if-then rules), the PI controllers' parameters given in Table 4 . The three linear subintervals $\left(S_{1}\right.$, $\left.S_{2}, S_{3}\right)$ were defined as the fuzzy sets, where $S_{1}=(12-16)$, $S_{2}=(16-23)$, and $S_{3}=(23-41)$, and form the universe of discourse. Figure 14 shows the adopted membership functions of the fuzzy sets. The TSF-PI controller predicts the values of $K_{p}$ and $K_{i}$ that would allow convenient control based on the Takagi-Sugeno fuzzy method. A diagram representing the TSF-PI controller principle is shown in Figure 15. The block diagram of the global proposed control scheme, using the TSF-PI controller and the voltage control balance, which would guarantee a good control over all operating points, is shown in Figure 16.

6.2. Global Stability Investigation. According to the Wong et al.'s theorem $[27,28]$, the closed-loop system-based TSF control is stable when the following conditions are satisfied: (i) the local stability has to be guaranteed; (ii) a complementary triangular membership function has to be selected for the fuzzy logic inputs, and (iii) the weighted average defuzzification method has to be used. In our case, the stability of the local PI controllers is ensured as they are synthesized using the Naslin method. This latter generally defines the characteristic ratios allowing the design of a controller satisfying the 


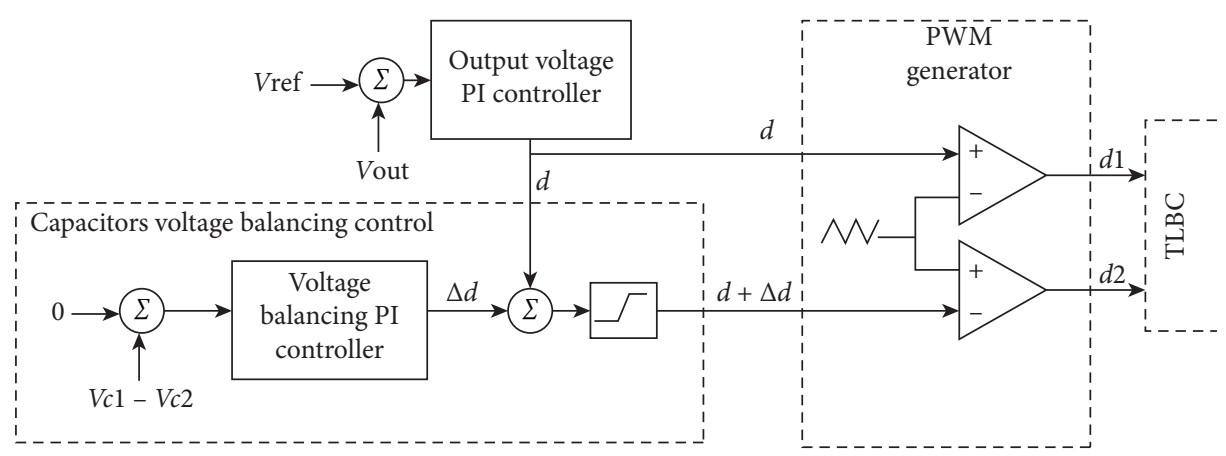

FIGURE 11: Block diagram of the global control scheme using PI controller.

TABLE 5: PI controller parameters corresponding to the three subintervals.

\begin{tabular}{lcc}
\hline & $K_{p}$ & $K_{i}=(1 / T i)$ \\
\hline$S_{1}$ & 0.068 & 127.55 \\
$S_{2}$ & 0.060 & 25.09 \\
$S_{3}$ & 0.0011 & 188.67 \\
\hline
\end{tabular}

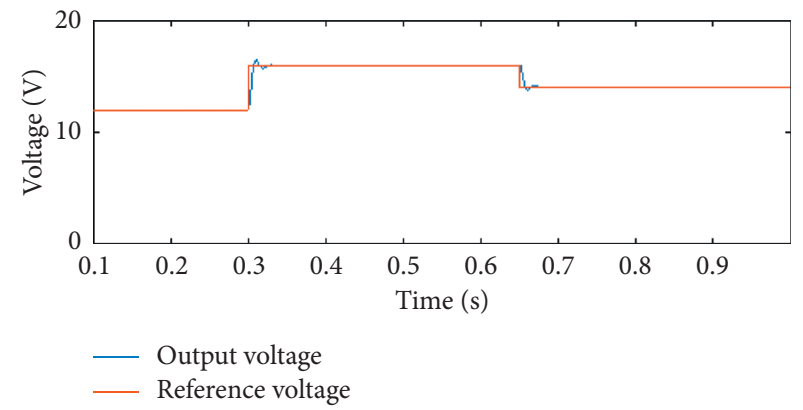

(a)

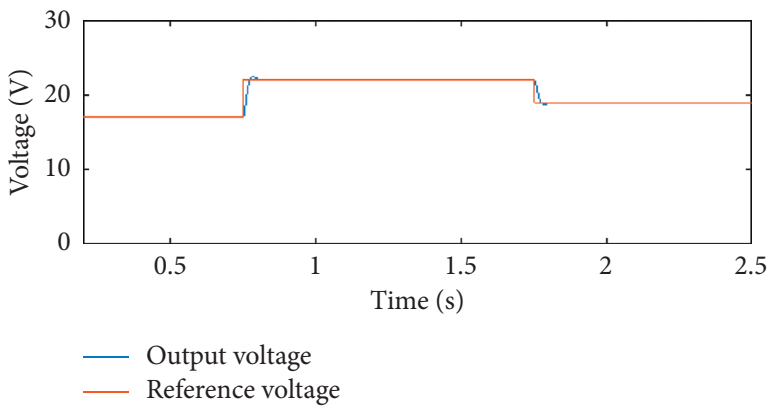

(b)

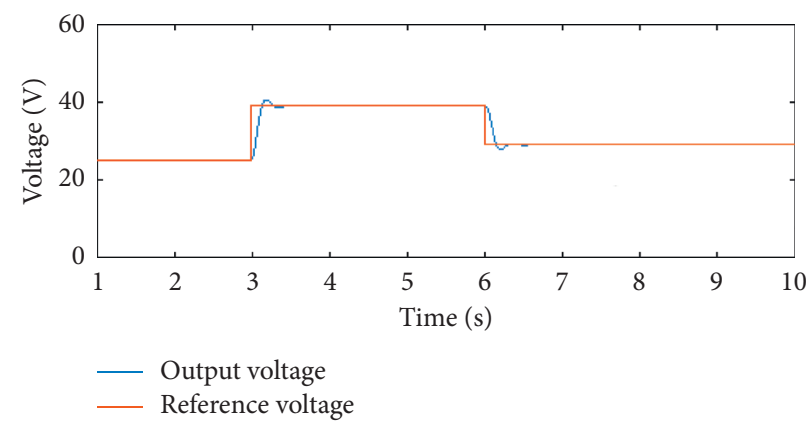

(c)

Figure 12: The closed-loop response with (a) $\mathrm{PI}_{1}$, (b) $\mathrm{PI}_{2}$, and (c) $\mathrm{PI}_{3}$ controllers to reference voltage change. (a) 12-16-14 V, (b) 17-22-19 V, and (c) $25-39-29 \mathrm{~V}$.

closed-loop stability [29]. These conditions were taken into consideration for TSF controller design, and hence the closed-loop system is globally stable.

6.3. Results and Discussion. In this section, experimental results validating the proposed control process and presenting great interest for practical applications are addressed. Three different scenarios were elaborated that are based on testing the proposed controller under set-point change and load disturbance.

The first scenario aims to test the reference tracking over the operating region of the converter. Reference has followed this sequence: $\quad(13 \mathrm{~V} \longrightarrow 18 \mathrm{~V} \longrightarrow 12 \mathrm{~V} \longrightarrow 15 \mathrm{~V} \longrightarrow 20 \mathrm{~V} \longrightarrow$ $27 \mathrm{~V} \longrightarrow 19 \mathrm{~V} \longrightarrow 22 \mathrm{~V} \longrightarrow 28 \mathrm{~V} \longrightarrow 38 \mathrm{~V} \longrightarrow 31 \mathrm{~V} \longrightarrow 41 \mathrm{~V}$ $\longrightarrow 28 \mathrm{~V})$ at $(13.73 \mathrm{sec}, 37.36 \mathrm{sec}, 52.93 \mathrm{sec}, 74.62 \mathrm{sec}, 92.17 \mathrm{sec}$, $107 \mathrm{sec}, 116.2 \mathrm{sec}, 135.2 \mathrm{sec}, 150.5 \mathrm{sec}, 165.7 \mathrm{sec}, 180.9 \mathrm{sec}$, and $190.1 \mathrm{sec})$, respectively. This long sequence was selected to cross 


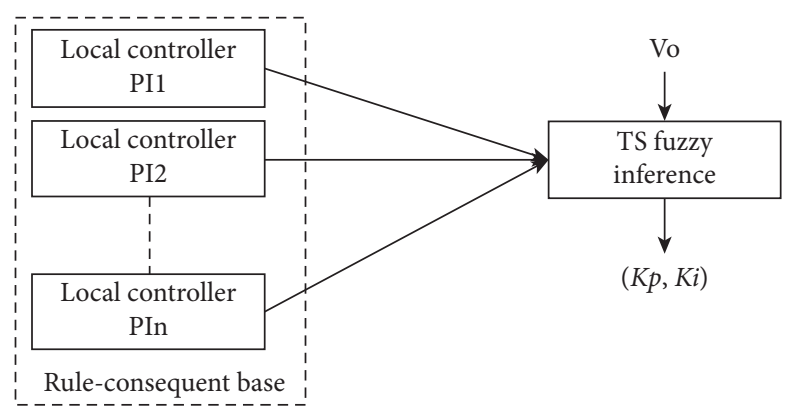

FIGURE 13: Structure of TS fuzzy controller.

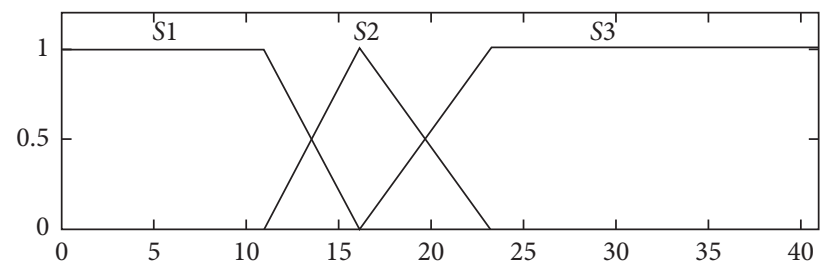

FIgURe 14: Fuzzy set membership functions of TSF-PI controller.

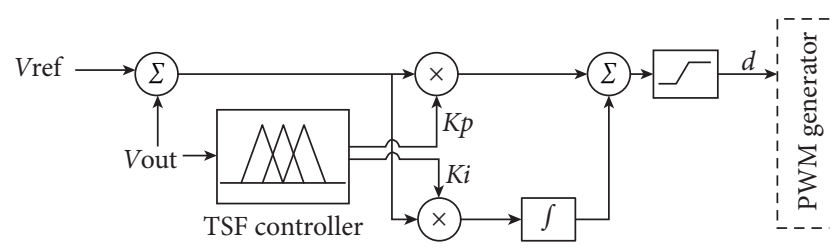

Figure 15: Diagram of the TSF-PI controller principle.

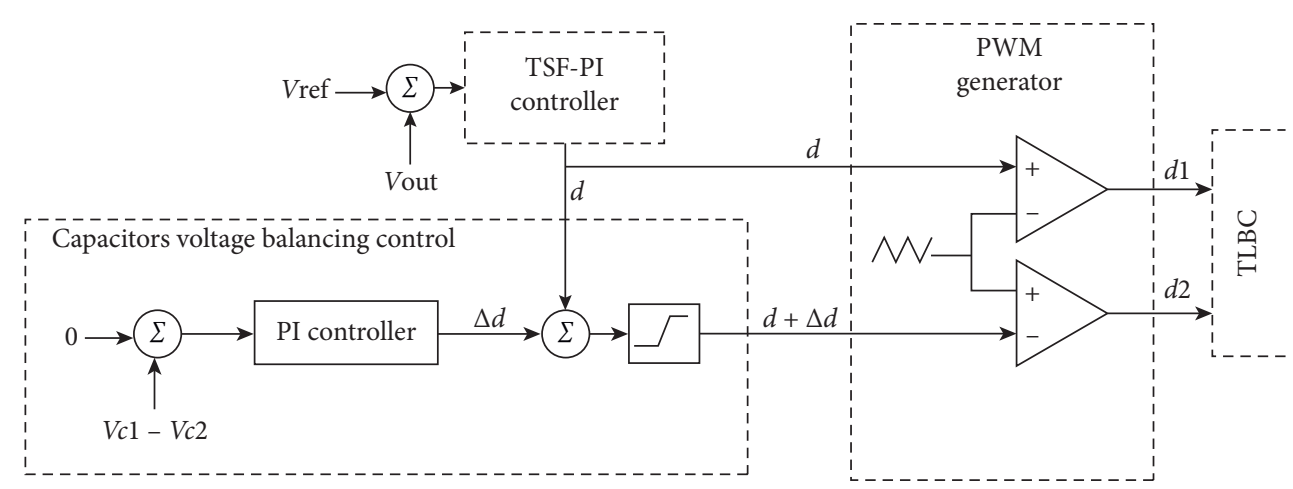

FIGURE 16: Block diagram of the global proposed control scheme.

different operating points in the three linear regions $\left(S_{1}, S_{2}\right.$, and $S_{3}$ ).

Under these step changes, the obtained results can verify the proposed control strategy based on TS fuzzy and reflect the TLBC circuit operating. From Figure 17, it is clear that a noteworthy improvement is achieved by using the proposed intelligent control structure. As expected, over the considered range (from $12 \mathrm{~V}$ to $41 \mathrm{~V}$ ), the converter output (Figure 17(a)) ensured a proper startup transient and high set-point (desired output) tracking capability with good accuracy and no overshoots or oscillations are introduced. It appears that whatever the set-point change, the performed control system can promptly reach the reference with a short transient settling time (approximately $0.3 \mathrm{~s}$ ). It can be also seen from the inductor current depicted in Figure 17(b) that the core saturation is avoided during the transient and the variations, which protect the power electronic devices from damage. Moreover, thanks to the integrated capacitor voltages balancing controller, the voltages across both capacitors $C 1$ and $C 2$ remain close to each other and equal half the output voltage (see Figure 17(c)). This means that the proper operating of the TLBC is guaranteed. Accordingly, the proposed control 


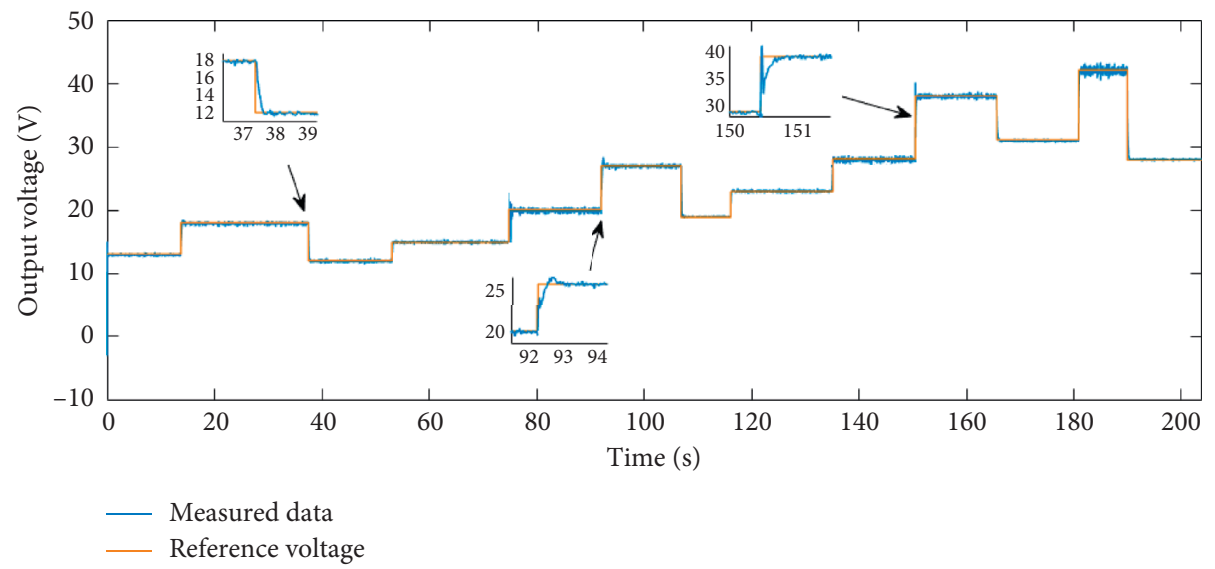

(a)

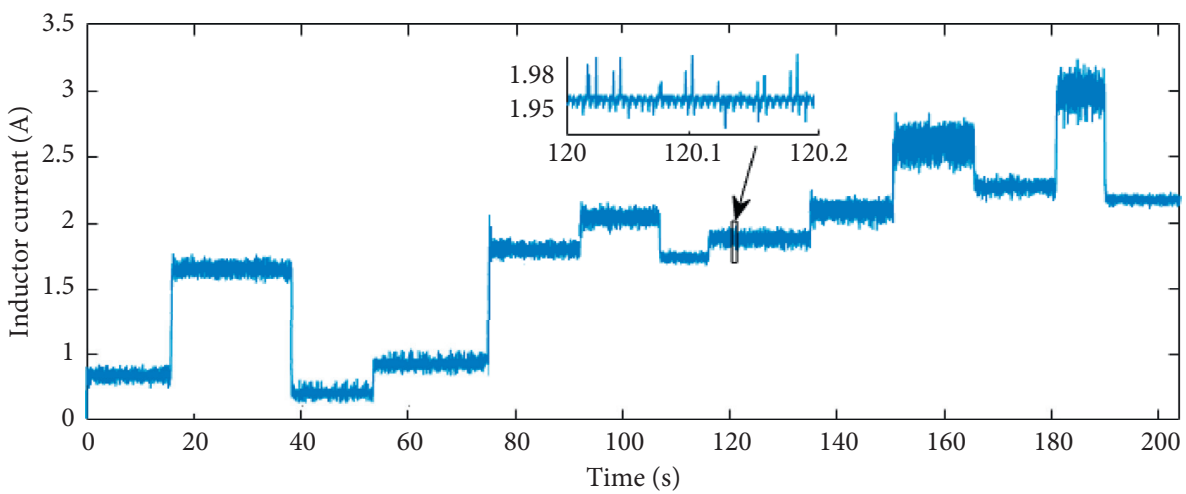

(b)

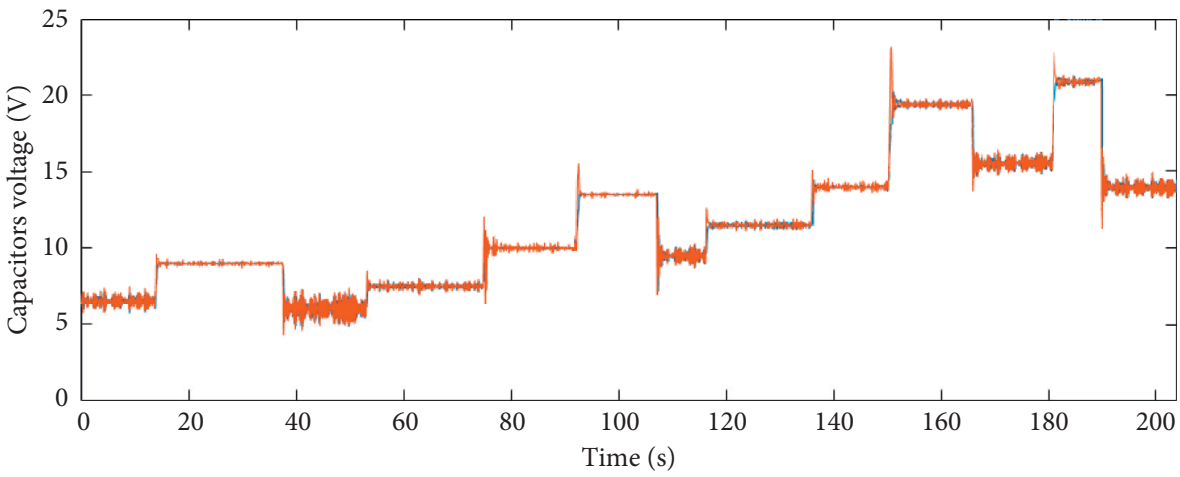

$-\mathrm{Vcl}$

Vc2

(c)

Figure 17: Experimental waveforms. (a) Output voltage. (b) Inductor current. (c) $V c 1$ and $V c 2$, resulted for reference voltage change: $13 \mathrm{~V} \longrightarrow 18 \mathrm{~V} \longrightarrow 12 \mathrm{~V} \longrightarrow 15 \mathrm{~V} \longrightarrow 20 \mathrm{~V} \longrightarrow 27 \mathrm{~V} \longrightarrow 19 \mathrm{~V} \longrightarrow 22 \mathrm{~V} \longrightarrow 28 \mathrm{~V} \longrightarrow 38 \mathrm{~V} \longrightarrow 31 \mathrm{~V} \longrightarrow 41 \mathrm{~V} \longrightarrow 28 \mathrm{~V}$

method performs well and meets excellent dynamic performance during output voltage reference tracking over the system operating range, which increases the system reliability. By implementing the proposed TSF-PI controller, the PI controller parameters vary in a way to obtain the optimal performances depending on the system operating state.

In the second scenario, an additional experiment on the same process aimed at even more evaluating the dynamic performance of the TSF-PI controller has been carried out. A sinusoidal signal expressed by $24+4 \sin (2 \pi 100 t)(V)$ is adopted as a voltage reference. It oscillates between $20 \mathrm{~V}$ and $28 \mathrm{~V}$, which means continuous variation between $S_{2}$ and $S_{3}$ zones. Figure 18 shows the resultant output voltage, the inductor current, and the capacitor voltages. It is clearly seen that the system tracks the changing reference perfectly and presents good performances over the considered operating zones, as well as satisfactorily maintaining the capacitor voltages balanced. 


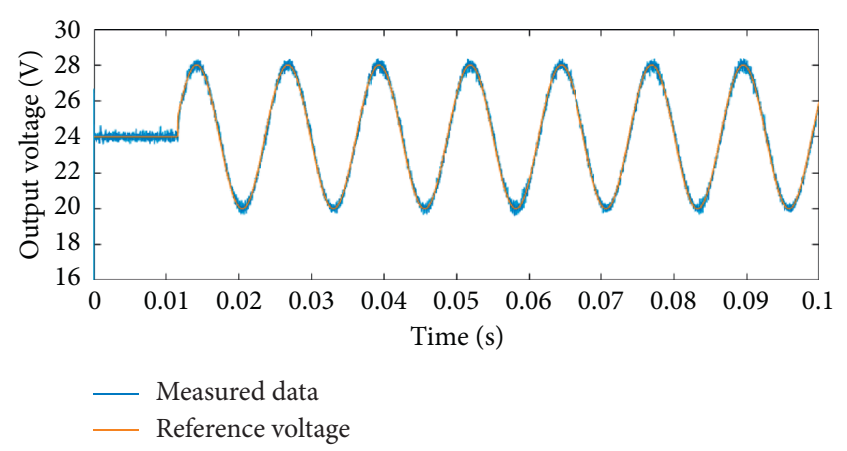

(a)

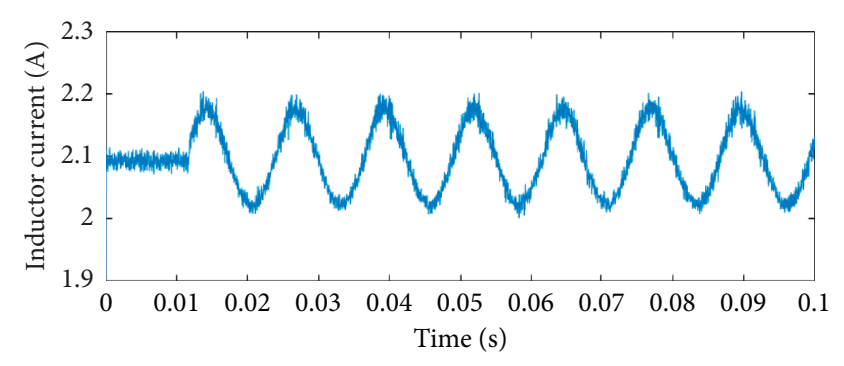

(b)

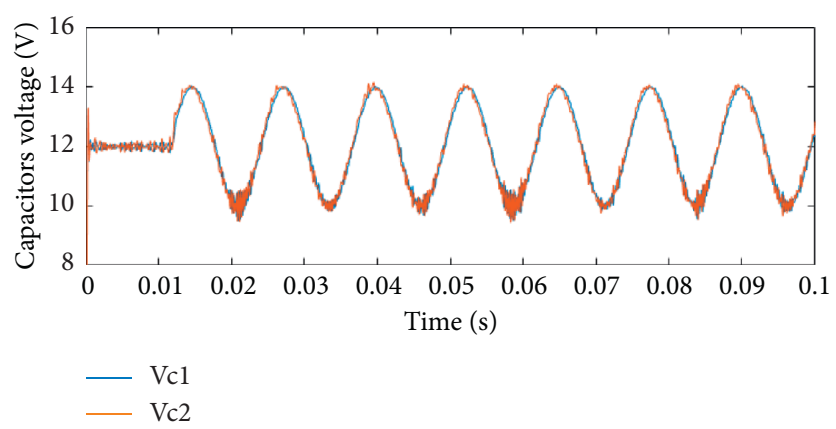

(c)

FIGURE 18: Experimental waveforms. (a) Output voltage. (b) Inductor current. (c) $V c 1$ and $V c 2$, resulted for a sinusoidal reference $24+4 \sin (2 \pi 100 t)$.

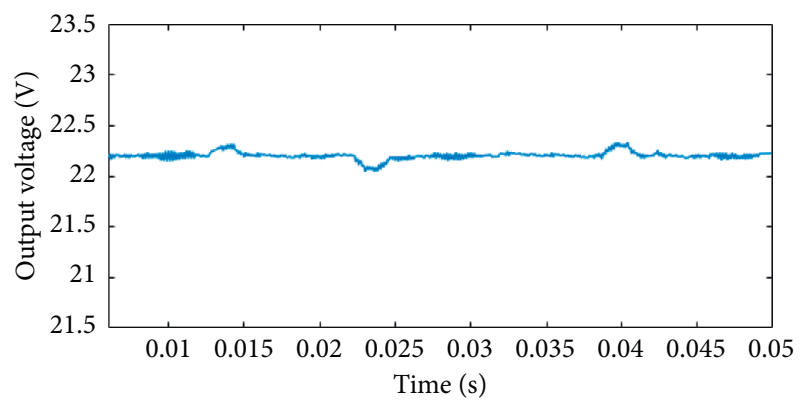

(a)

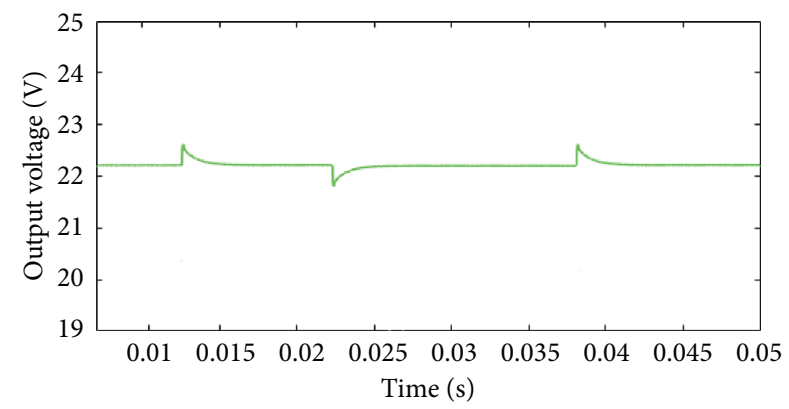

(c)

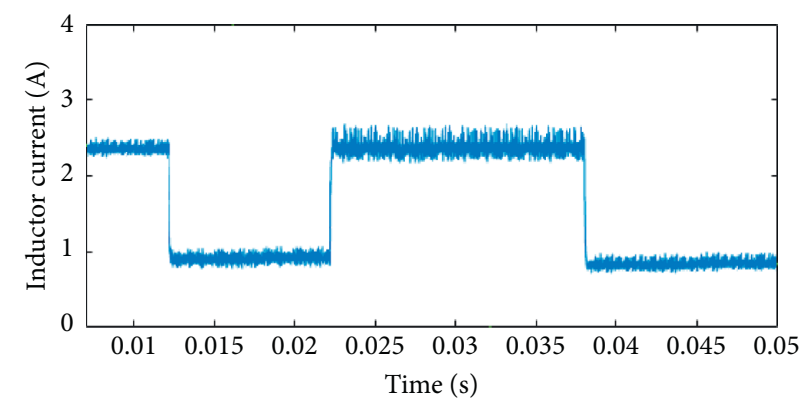

(b)

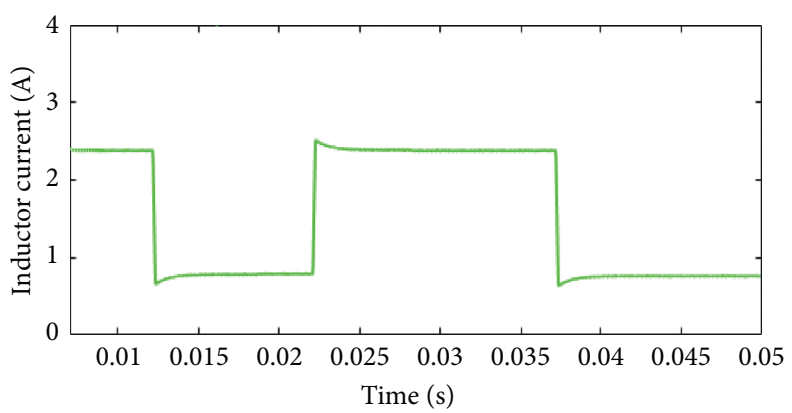

(d)

FIGURE 19: Evaluation of the proposed controller performance under load disturbance: experimentally (a) output voltage and (b) inductor current and in simulation (c) output voltage and (d) inductor current.

Lastly, in the third scenario, the load disturbance rejection capability of the proposed controller is examined as it is considered a good indicator of the general controller performance. For a set point of $22.2 \mathrm{~V}$, the resistive load has been changed from its nominal value of $24.7 \Omega$ to $50 \Omega$ (twice) at $t=0.012 \mathrm{~s}$ and $t=0.038 \mathrm{~s}$ and from $50 \Omega$ to its 
nominal value at $t=0.022 \mathrm{~s}$. Plots of the system output voltage and the inductor current for both experiments and simulation under MATLAB/Simulink are shown in Figure 19. It can be seen that in all cases, the proposed controller is able to cope with the load disturbances. The system output returns promptly to its steady state within $2.4 \mathrm{~ms}$, and no overshoots are introduced in the resultant inductor current. This reveals the good robustness against load disturbance achieved by the proposed controller. Note that a close agreement between simulation and experiments has been obtained. The difference between them in terms of the amplitude of the oscillations on the current is owing to the measurement noise and the imprecision in the value of the physical parameters.

\section{Conclusion}

This research work aims to design and experimentally implement an efficient control strategy ensuring the output voltage tracking, the system stability, and the capacitor voltages balance for a DC-DC TLBC.

An overview of the TLBC topology and its operating principle was firstly presented. Secondly, an identification of the converter through the multimodel representation based on the transfer function model was examined. Then, a local control around given operating points, using classical PI controllers, was synthesized, which simply enables the design of a flexible TS fuzzy-based controller with strong adaptability over the system operating range. An experimental TLBC prototype was utilized to verify the feasibility of the proposed control strategy. The control law is implemented under MATLAB/Simulink environment and executed in real time through the dSPACE (DS1104) board. The experimental validation has emphasized the good performance of the proposed controller in terms of robustness, tracking accuracy, and reliability over the entire domain of operation under significant set-point changes and load disturbances. In addition, in this study, we have used a simple PI controller for capacitor voltage balancing, which ensures the appropriate operation of TLBC. However, a more advanced controller can be developed to guarantee high balancing performances and very optimal operating of the TLBC, which can be considered in a further work.

\section{Data Availability}

The data used to support the findings of this study are available from the corresponding author upon request.

\section{Conflicts of Interest}

The authors declare that they have no conflicts of interest regarding the publication of this paper.

\section{Acknowledgments}

This research work was financially supported by the National Center for Scientific and Technical Research (CNRST, Morocco).

\section{References}

[1] M. Forouzesh, Y. P. Siwakoti, S. A. Gorji, F. Blaabjerg, and B. Lehman, "Step-up DC-DC converters: a comprehensive review of voltage-boosting techniques, topologies, and applications," IEEE Transactions on Power Electronics, vol. 32, no. 12, pp. 9143-9178, 2017.

[2] F. Asadi, K. Eguchi, and J. Hudgins, "Dynamics and control of DC-DC converters," Synthesis Lectures on Power Electronics, Morgan and Claypool, vol. 6, no. 1, pp. 1-241, 2018.

[3] M. D. Bougrine, A. Benalia, and M. H. Benbouzid, "Simple sliding mode applied to the three-level boost converter for fuel cell applications," in Proceedings of the 2015 3rd International Conference on Control, Engineering \& Information Technology (CEIT), Tlemcen, Algeria, May 2015.

[4] Z. Guo, M. Zarghami, S. Hou, and J. Chen, "Model predictive control for three-level boost converter in photovoltaic systems," in Proceedings of the 2017 North American Power Symposium (NAPS), Morgantown, WV, USA, September 2017.

[5] P. Thounthong, S. Sikkabut, P. Sethakul, and B. Davat, "Model based-control of three-level boost converter for fuel cell applications," in Proceedings of the 2011 10th International Conference on Environment and Electrical Engineering, Rome, Italy, May 2011.

[6] K. Mehran, D. Giaouris, and B. Zahawi, "Stability analysis and control of nonlinear phenomena in boost converters using model-based takagi-sugeno fuzzy approach," IEEE Trans. On Circuits and Systems I: Regular Papers57, vol. 57, no. 1, pp. 200-212, 2010.

[7] R.-C. Roman, R.-E. Precup, and E. M. Petriu, "Hybrid datadriven fuzzy active disturbance rejection control for tower crane systems," European Journal of Control, vol. 58, pp. $373-387,2021$.

[8] M. Truntič, A. Hren, M. Milanovič, and M. Rodič, "Adaptive fuzzy-logic state controller for DC-DC step-down converter," Electrical Engineering, vol. 100, no. 2, pp. 983-995, 2018.

[9] A. G. Saravanan and M. Rajaram, "Fuzzy controller for dynamic performance improvement of a half-bridge isolated DC-DC converter," Neurocomputing, vol. 140, pp. 283-290, 2014.

[10] M. Leso, J. Zilkova, M. Pastor, and J. Dudrik, "Fuzzy logic control of soft-switching DC-DC converter," Elektronika Ir Elektrotechnika, vol. 22, no. 5, 2016.

[11] R. Toscano, "Structured controllers for uncertain systems: a stochastic optimization approach," Advances in Industrial Control, Springer, Berlin, Germany, 2013.

[12] I. Salhi, S. Doubabi, N. Essounbouli, and A. Hamzaoui, "Application of multi-model control with fuzzy switching to a micro hydro-electrical power plant," Renewable Energy, vol. 35, no. 9, pp. 2071-2079, 2010.

[13] C. Jamroen, P. Namproom, and S. Dechanupaprittha, "TSfuzzy based adaptive PEVs charging control for smart grid frequency stabilization under islanding condition," Procedia Computer Science, vol. 86, pp. 124-127, 2016.

[14] H. Vanjani, U. K. Choudhury, M. Sharma, and B. Vanjani, "Takagi-sugeno (TS)-type fuzzy logic controller for threephase four-wire shunt active power filter for unbalanced load," in Proceedings of the IEEE 7th Power India International Conference (PIICON), Bikaner, India, November 2016.

[15] S. El Beid and S. Doubabi, "DSP-based implementation of fuzzy output tracking control for a boost converter," IEEE Transactions on Industrial Electronics, vol. 61, no. 1, pp. 196-209, 2014. 
[16] H. Doubabi, I. Salhi, M. Chennani, and N. Essounbouli, "Voltage control of DC-DC Three level Boost converter using TS Fuzzy PI controller," in Proceedings of the IEEE 6th International Conference on Control, Decision and Information Technologies (CODIT), Paris, France, April 2019.

[17] C. Kang, W. Wang, W. Li, H. Du, and L. Diao, "Balance midpoint potential control of three-level boost converter for rail transit application," IEEE Access, vol. 7, pp. 47737-47746, 2019.

[18] H.-C. Chen and J.-Y. Liao, "Design and implementation of sensorless capacitor voltage balancing control for three-level boosting PFC," IEEE Transactions on Power Electronics, vol. 29, no. 7, pp. 3808-3817, 2014.

[19] M. Phattanasak, "Étude, modélisation et mise en oeuvre de convertisseurs DC-DC isolés multiport et modulaires," $\mathrm{PhD}$ thesis, Lorraine University, p. 11, 2020, https://hal.univ-lorraine. fr/tel-01749387.

[20] X. Ruan, B. Li, Q. Chen, S-C. Tan, and C. K. Tse, "Fundamental considerations of three-level DC-DC converters: topologies, analyses, and control," IEEE Transactions on Circuits and Systems I: Regular Papers, vol. 55, no. 11, pp. 3733-3743, 2008.

[21] D. Oulad-Abbou, S. Doubabi, and A. Rachid, "Power switch failures tolerance of a photovoltaic fed three-level boost DCDC converter," Microelectronics Reliability, vol. 92, pp. 87-95, 2019.

[22] C. T. Chuang, M. Arienzo, D. D.-L. Tang, and R. D. Isaac, "A Schottky-barrier diode with self-aligned floating guard ring," IEEE Transactions on Electron Devices, vol. 31, no. 10, pp. 1482-1486, 1984.

[23] F. De Stasi, Working with Boost Converters, Texas Instruments, Application Report, SNVA731-June, 2015.

[24] A. Nouri, I. Salhi, E. Elwarraki, S. E. Beid, and N. Essounbouli, "DSP-based implementation of a self-tuning fuzzy controller for three-level boost converter," Electric Power Systems Research, vol. 146, pp. 286-297, 2017.

[25] P. Naslin, Essentials of Optimal Control, Boston Technical Publishers, Inc., Cambridge, MA, USA, 1969.

[26] A. Farrell and M. Polycarpou, Adaptive Approximation Based Control: Unifying Neural, Fuzzy and Traditional Adaptive Approximation Approaches, John Wiley \& Sons, Hoboken, NJ, USA, 2006.

[27] L. K. Wong, F. H. F. Leung, and P. K. S. Tam, “A fuzzy sliding controller for nonlinear systems," IEEE Transactions on Industrial Electronics, vol. 48, no. 1, pp. 32-37, 2001.

[28] L. K. Wong, F. H. F. Leung, and P. K. S. Tam, "Lyapunovfunction-based design of fuzzy logic controllers and its application on combining controllers," IEEE Transactions on Industrial Electronics, vol. 45, no. 3, pp. 502-509, 1998.

[29] Y. C. Kim, L. H. Keel, and S. P. Bhattacharyya, Characteristic Ratio Assignment: An Application to a Benchmark Problem, IFAC Robust Control Design, Milan, Italy, 2003.

[30] A. Mustafa and S. Mekhilef, "Dual phase LLC resonant converter with variable frequency zero circulating current phase-shift modulation for wide input voltage range applications," IEEE Transactions on Power Electronics, vol. 36, no. 3, pp. 2793-2807, 2020.

[31] P. Akter, M. Uddin, S. Mekhilef, N. M. L. Tan, and H. Akagi, "Model predictive control of bidirectional isolated DC-DC converter for energy conversion system," International Journal of Electronics, vol. 102, no. 8, pp. 1407-1427, 2015.

[32] S. M. S. I. Shakib and S. Mekhilef, "A frequency adaptive phase shift modulation control based LLC series resonant converter for wide input voltage applications," IEEE Transactions on Power Electronics, vol. 32, no. 11, pp. 8360-8370, 2017.

[33] B. L. Dokić and B. Blanuša, Power Electronics: Converters and Regulators, Springer International Publishing AG, Cham, Switzerland, Third Edition, 2016. 